instrument was first recommended to the profession, I endeavoured to make use of Stafford's small catheter and silver wire, but I met with many cases of stricture in which this instrument could not be introduced, but in which a small catgnt bougit passed readily, probably from some tortuosity or other irregularity of the urethra, which the flexibility of this material enabled it to traverse. I then had catgut bougies of double length constructed, and hove used them for more than twenty years with considerable success in narrow or close strictures. A gnm-elastic catheter once introduced into the bladder, and retained there for two or three days, may afterwards in most cases be replaced by larger instruments, at short intervals, without a conductor, and in about ten days or a fortnight a catheter of the size of No. 10 or 12 can be readily introduced. This latter part of the treatment, however, has been long known and practised by the profession, and it is scarcely necessary to inform the Sub-Editor of The LaNCET that it is by absorption, as well as by dilatation, that the cure of stricture is in this manner effected.

I am, Sir, your obedient servant,

Gardiner's-place, Dublin, Dec. 1856.

EDward Hutron.

* * As Dr. Hutton has himself described the difference which exists between the instruments he employs and those which have been invented by Mr. Thomas Wakley, it is unnecessary for us to refer further to the suhject. Dr. Hutton does not appear to be aware that the instruments he has so long used are precisely identical with the instruments used by Desault almost half a century ago. The elastic catheters and catgut cords, or bougies, kindly sent to us by Dr. Hutton, have been received; but how it has happened that strictures of the urethra have ever been cured by such instruments, we are quite at a loss to understand. A letter from Mr. Thomas Wakley, in which is given Bichat's description of the flexible catheters used by Desault, will be published next week. It was placed in our hands a fortnight since, as a reply to the communication of Dr. Barton, whose second letter it cannot be now necessary to publish, Dr. Hatton having himself entered the field as his own champion. -SuB-ED. L.

\section{THE TUBULAR TREATMENT OF STRICTURES OF THE URETHRA.}

(NOTK FROM MR. J. L. MILTON.)

To the Editor of The LANCET.

Sir, - I am at a loss to understand how two operations so totally different as M. Maisonneuve's and that introduced by Mr. 'T. Wakley could be confounded together, there being as much dissimilarity between them as any two systems adapted to the same disease in the same part conld present. It would be just as reasonable to say that Mr. T. Wakley's method was like those of Mr. Barnard Holt or Dr. Arnutt, or that he has no title to priority because he did not first discover that it was necessary to dilate a stricture at all.

In the summer of 1847, I attended M. Maisonneuve's course of lectures at the Ecole Pratique, and was present when he demonstrated to his class his plan of introducing a threaded bougie. But this operation was simply brought forward as a last resource, to be used when no other instrument, even the smallest bougie, could be passed through the stricture; no mention was ever made of its possessing the least value as a means of cure. The only object sought for was to avoid the danger arising from retention of the urine; the subsequent, the curative, treatment was ordinary dilatation. It was an excellent and ingenious plan; but M. Maisonneuve never sought to exalt it to the rank of anything more than an expedient in cases of almost impermeable strictures.

Dr. Barton's attempt to claim priority for Dr. Hutton is equally unfounded. The proceeding described is totally different; moreover, it is clumsy and defective in the extreme, and, as I have tried it, I have little hesitation in saying that a gum-elastic catheter could not be passed in this way through a very tight stricture; ${ }^{*}$ even the elastic urethral tube, with its wedge-like point, can only be introduced in sach a case with the greatest difficulty when catgut is used. Whereas with $\mathrm{Mr}$. T. Wakley's instrument, if the guiding rod can be got through, the operator gains such a vast control over the canal, that no amount of contraction could resist it. I have passed it through *Mr. Barrington says very truly, it was passed "seemingly through the
stricture." a stricture so tight and retractile, that a flexible tube has in the course of a single night been nearly cut through in part of its circumference.

Having seen Mr. T. Wakley operate several times at the Royal Free Hospital, and having repeatedly used the instrument myself, I have great pleasure in expressing my unqualified opinion of its superiority over every other means of treatment I have seen adopted. That it may fail to cure in some rare cases of retractile stricture, is just possible; but in every other form of contraction, however complicated and severe, it may be relied on as a certain, rapid, and perfectly safe means of cure, and even in those refractory cases, which are neither amenable to caustic nor dilatation, it will always, if properly used, afford relief.

Like other inventors, Mr. T. Wakley must expect to suffer from that "pernicious erudition" which has in every age furnished misdirected ingenuity with the means of proving irrefragably that each successive discovery was simply pirated from some obscure or defunct predecessors-a process more satisfac. tory and far more easy than that of testing its merits. And even granting that there were any foundation for a claim of priority on the part of some other person, which is not the case here, to whom is the most credit due? To the man who launches into the world a crude, unfinished idea, or to him who, starting from the same point, perfects and utilizes his method to the utmost extent its nature admits of ?

I have the honour to remain, Sir, yours obediently, Castle-street, January, 1857.

J. L. MiltoN.

\section{AN ASPHYXIATED NEWLY - BORN INFANT RESTORED BY “MARSHALL HALL'S READY METHOD" OF TREATMENT.}

\section{To the Editor of THE LANCET.}

SIR,-If you think another case of asphyxia successfully treated by the "Marshall Hall method" worthy of notice, please to give it a corner in your widely-circulated journal.

At three o'clock A.M. on December 29 th, I was called to a case of placental presentation. On arriving at the house of my patient, I found her in an alarming state of syncope from excessive hæmorrhage. I immediately attempted delivery by turning; the child (a boy) being large, I had a good deal of difficulty in liberating the head from its pelvic prison, some considerable time and much exertion on my part being required, the mother having no uterine pains to assist in the expulsion.

When the child was born, I observed it was perfectly asphyxiated; but my chief anxiety being to do all I could for the mother, my attention was not directed to the infant for several minutes. It then appeared quite inanimate. However, thinking it a good opportunity to try "Dr. Marshall Hall's method" in cases of asphyxia, I proceeded according to the plan laid down by him, and after persevering unremittingly for a quarter of an hour, the child gave a slight and short inspiration, and in three minutes more another inspiration took place; after this the infant breathed once in a minute for a short time, and then more frequently and deeply; at length he opened his eyes, and at the expiration of half an hour he breathed freely, and cried as strongly as could a healthy child.

Two female friends of the patient were present, and they frequently expressed a positive opinion that it would be perfectly useless to continue any attempts at resuscitation, the nurse at the same time exclaiming, "Ah, Sir, you may turn and twist that child about as much as you like, but you will never bring it to life." Their surprise was great indeed when at length the child began to show signs of animation.

I take to myself no credit in the treatment of this case, being merely an humble follower of the scientific and valuable directions given by Dr. Marshall Hall.

I am, Sir, your obedient servant,

Wendover, January, 1857.

J. T. SAVORY.

\section{To the Editor of THE LANCET.}

SIR,-Having hut lately returned from Paris, I only saw your number of December 13th a few days ago, in which you object to the title of " the Ready Method," as likely to lead to " uncertainty of action" and "to some confusion of practice," and consider the designation of "Marshall Hall's Method" a better one. In correspondence with Dr. Marshall Hall, for whom I had been one of the first to put to the test the superior efficacy of the postural method, by repeated experiments at St. George's Hospital, I used the name which he did me the honour to adopt. Seeing your article of Dec. 13th, 
I wrote to Dr. Marshall Hall, asking him to change it for yours, wishing, as you do, that his name "should be benevolently associated with the Method to the end of time." $\mathrm{He}$ has since consented to the process receiving the name of "Marshall Hall's Ready Method." It not only inclades the great discoverer's name, but shows that the Method is one applicable at any moment, in any place, requiring no apparatus whatever.

I remain, Sir, your obedient servant, Charles Hunter, M.R.C.S., I A.C.

Wilton-place, Jan., $185 \pi$.

\section{THE MODE OF RESUSCITATING NEW-BORN CHILDREN IN SCOTLAND.}

To the Editor of THE LANCET.

SrR, - I beg to assure you that the newly-promulgated method of Dr. Marshall Hall, as far as the resuscitation of new-born children is concerned, has been in practice from time immemorial in the Highlands of scotland, where it is popularly called the "bringing alive again," and has been almost invariably successful in cases of newly-born asphyxiated children, from long-continued labour, mechanical delivery, or where the circulation has been impeded by straining of the funis umbilicus, or complicated presentations. It has not, however, been found to answer in cases in which death had taken place with the nell-marked signs, from twenty to forty minutes before death.

As the mode of procedure is somewhat different to that submitted by Dr. Marshall Hall, and as it is likely to answer better, particularly in warm weather, having also long experience on its side, I will describe it.

As soon as the child is born, and before the funis is divided, if it is found to be asphyxiated. Whisky is immediately dashed on the chest, sprinkled on the cheek, and rubbed on the sides of the neck up to the back of the ears; and until the first supply is dried up, it is sufficient to blow with the mouth from time to time, which is equal to more dashing. The finger is put into the mouth to remove foreign matters from the fauces; artificial respiration being kept up by raising and depressing the chest by lateral pressure; smart slaps are given to the nates occasionally, to stimulate the diaphragm. Sometimes it is found useful to allow a small quantity of blood to escape from the umbilicus. Whisky produces a greater amount of cold, and, by its evaporation, keeps it up longer than water; and, as must be obvious, is more stimulating to the extremities of the nerves, and more powerful in inducing reflex motor action, and so establishing a function so essential to life as respiration. Cold water is little better in most places in summer than warm water in winter; and there can be no doubt that those who give it a fair trial will find it an improvement.

Beanly, Jan. $185 \tilde{7}$. I remain, Sir, yours, \&c.

K. Corbet, M.D., Surgeon.

\section{ON THE DIAGNOSIS OF PRIMARY SYPHILIS REQUIRING MERCURIAL TREATMENT.}

\section{To the Editor of THE LANCET.}

Sin, - Your journal of the 27 th Dec. contains a letter from Mr. Stapleton, of Dublin, in which he offers some comments upon an article of mine in the October number of the British and Foreign Quarterly Review. Mr. Stapleton complains that the facts which he has enunciated have not been fairly representod in the article in question. The quotations, however, therein contained, as illustrating Mr. Langston Parker's opinions (and to these only my observations refer) are correctly given, and if Mr. Stapleton's meaning is not clear, the fault does not rest with me.

At page 15 of Mr. Langston Parker's work on Syphilitic Diseases, he says that there are several circumstances which particularly indicate the use of mercury in primary syphilis; and under the fourth head Mr. Parker includes all primary sores which have yielded a characteristic pustule by inocnlation. "The indication," he says, "for the employment of mercury is still more pressing if the primary sore be accompanied by bubo."

By the unqualified term "bubo" I understood "a swelling in the lymphatic glands from acute or chronic inflammation."

Mr. Stapleton, however, says that Mr. Langston Parker here means " multiple indolent bubo, consequent upon indurated chancre." If such should prove to be the case, it is very desirable that those who read MI. Parker's widely-circulated and in many respects very valuable work, should be made acquainted with the true meaning of the word; for I have good reason to know that both surgeons and pupils are often in the habit of prescribing mercury for primary syphilitic affections, accompanied by inflammatory bubo, and believe that by so doing they are following Mr. Langston Parker's injunctions. The answer to Mr. Stapleton is, that what he represents as Mr. Parker's meaning, appears, upon the face of it, simply, not to be the fact.

Let us hear the description of a bubo treated according to Mr. Langston Parker's plan, at p. 68 of his work "On the Treatment of Syphilis." After a trifling primary affection in this case, it appeared probable that the bubo would suppurate. The "glands were as large as a tarkey's egg, and at the summit, exceedingly painful and tender; and from a feeling of fiuctuation given to the finger, it appeared probable that matter had already formed." Does this description in any way accord with the multiple indolent bubo mentioned by Mr. Stapleton?

Again, in all the editions of Mr. Langston Parker's work, he states, that it is of great importance that a bubo shonld not be allowed to suppurate; and that " unless specially contra. indicated, mercury may be employed to assist the resolution of the tumour."

In the face of such assertions as these, upon what authority, I ask, does Mr. Stapleton say that by the term "bubo," Mr. Langston Parker means " the multiple indolent bubo, consequent upon indurated chancre" ?

The importance of the subject alone leads me to repeat, in opposition (as it appears to me) to the published views of $\mathrm{Mr}$. Langston Parker, that neither the existence of bubo, nor the production of a characteristic pustule by inoculation, is a valid reason for the administration of a mercurial course in primary syphilis.

Some expressions are used in Mr. Stapleton's letter little adapted for scientific inquiry. It must always be regretted when such are introduced into professional discussions, and $\mathrm{l}$ must be excused if I refrain from further noticing them; I have therefore confined my observations to the points of scientific interest referred to in Mr. Stapleton's letter, and these have now been fully answered.

Dover-street, Piccadilly, Jan. 1857 I remain, Sir, yours, \&c., H. LEE, F.R.C.S.

\section{THE HON. EAST INDIA COMPANY'S MEDICA工 SERVICE.}

To the Ealitor of The Lancet.

SIR,-Within the last two years I have observed a number of letters, appearing at intervals in THE LANCET, with such sirnatures annexed as " One of the Delnded," all condemnatory of the East India Company's Medical Service, representing it as a field in which the army surgeon is quite inadequately remunerated for his labours, and where disappointment alone awaits the "deluded" one. I have none of these letters now before me, but such I recollect to be their tenour. I protest against these assertions, through which I conceive our service to be utterly misrepresented.

That the writers of those letters were individually unfortumate $I$ do not in the least doubt, and that every service must unhappily contain some on whom a disproportionate amount of hardship falls, I am equally certain; but it is not from the point of view of these exceptional members that the service should be represented in public papers, or contemplated by those stepping over its threshold. Nor do I mean to assert that there is not a number of minor evils existing in our service, but these, not being essential to its nature, are remediable, and we may hope several of them will be found to have disappeared with the "new rules" which, framed and recommended by the late Governor-General, are said to be about to be immediately published.

That expatriation to the East Indies at all is a great evil, is undeniable; but, being voluntary, is no more to be made a theme of public complaint than désillusionnement after mar riage. There are persons and books at home capable of giving a truthful account of our service, quite sufficient to dissipate any air-castles, whose fabric has been drawn from mendacious tales of the " gorgeous East."

I have observed that the majority of these disappointed writers are of the Bombay and Madras Presidencies; these, it is true, have comparatively few staff appointments (beyond the usual charge of an infantry regiment) as prizes to be won, still the general course of the medical officer's career in those services cannot be materially different from the same in the Bengal 